\title{
Optimal management of subfertility in polycystic ovary syndrome
}

This article was published in the following Dove Press journal:

International Journal of Women's Health

13 June 2014

Number of times this article has been viewed

\author{
Joshua J Berger \\ G Wright Bates Jr \\ University of Alabama at Birmingham, \\ Department of Obstetrics and \\ Gynecology, Division of Reproductive \\ Endocrinology and Infertility, \\ Birmingham, AL, USA
}

\begin{abstract}
The purpose of this paper is to provide a stepwise approach to treating the infertility/ subfertility associated with polycystic ovary syndrome. Defining polycystic ovary syndrome in a patient requires first investigating other possible causes for polycystic ovary morphology, acne, hirsutism, obesity, and the metabolic derangements that often accompany polycystic ovary syndrome. Beginning with lifestyle modification and use of metformin, the progressive inclusion of more intensive therapies for induction of ovulation is described. Second-line treatments are discussed and the new findings from a large multicenter trial are discussed in the context of evidence-based treatment strategies for first-line agents. Finally, monofollicular development as a treatment goal and in vitro fertilization are discussed for those with recalcitrant disease.

Keywords: polycystic ovary syndrome, infertility, metformin, ovarian drilling, ovulation induction, subfertility
\end{abstract}

\section{Introduction}

Polycystic ovary syndrome (PCOS) may be the most common endocrine disorder in reproductive-aged women with a prevalence of $8 \%-18 \% .^{1}$ This number changes little when comparing different races or ethnicities, ${ }^{2-4}$ although the phenotypic expressions do differ slightly. ${ }^{5}$ The syndrome gets its name from the polycystic appearance of the ovaries that result from arrested follicular development and ovulatory dysfunction. Although the very name, PCOS, focuses on the ovary, this syndrome is associated with a wide range of reproductive and metabolic disorders. The metabolic concerns include obesity, type 2 diabetes mellitus, dyslipidemia, hypertension, and cardiovascular disease. ${ }^{5-7}$ Reproductive health issues include abnormal uterine bleeding, endometrial abnormalities, and infertility. Patients with PCOS commonly present to health care providers for acne, hair growth, and weight gain. Although not required diagnostic criteria, up to $95 \%$ of women with PCOS also have menstrual irregularities such as oligomenorrhea or amenorrhea, ${ }^{8}$ thus making PCOS one of the most common causes of infertility. The wide spectrum of clinical presentations, including subfertility, require individualized treatment approaches. Although the diagnosis of PCOS is fraught with controversy, a basic understanding of the most common criteria is crucial to effective management of the condition.

Since its description in the medical literature by Stein and Leventhal, ${ }^{9}$ there have been numerous attempts to define and standardize the diagnostic criteria for this syndrome. However, after four consensus workshops consisting of many of the world's experts on PCOS, there is still no standard definition of the disorder. ${ }^{10-13}$ The classic criteria, developed at a US National Institutes of Health (NIH) consensus conference, ${ }^{14}$ 
require chronic anovulation and clinical or biochemical signs of hyperandrogenism and absence of other metabolic/ endocrine causes for the diagnosis of PCOS. The Rotterdam criteria $^{12}$ focus on the clinical picture of polycystic ovarian morphology on ultrasound, a history of ovulatory disorders with menstrual irregularity, and clinical/biochemical signs of hyperandrogenism requiring two of three features with a few caveats. Although the Rotterdam criteria are commonly used in patient care, there are potentially nine different phenotypes ${ }^{15}$ representing a wide spectrum of disease and requiring different treatment approaches. The Androgen Excess-Polycystic Ovary Syndrome Society criteria, ${ }^{15}$ and their subsequent revisions, ${ }^{10,16}$ stress hyperandrogenemia as the primary pathophysiologic feature. Although it has been demonstrated that women who fulfill the original NIH criteria are at higher risk in terms of metabolic dysfunction when compared with the Rotterdam criteria, ${ }^{5}$ it is unclear how much the various criteria predict infertility, given that a lack of normal menstrual pattern, and thus ovulatory dysfunction, is a component of each (Table 1).

\section{PCOS and infertility}

The principal clinical manifestations of PCOS are hyperandrogenism and ovulatory dysfunction. Thus, many patients seek medical treatment for acne, hirsutism, and irregular or absent menses. The underlying pathophysiology is beyond the scope of this paper, but there is interplay between the perpetually elevated levels of androgens (both locally and peripherally), insulin sensitivity, and the hypothalamicpituitary-axis. It is the lack of regular ovulation that often

Table I Diagnostic criteria for PCOS

\begin{tabular}{lll}
\hline $\begin{array}{l}\text { I990 NIH } \\
\text { criteria }\end{array}$ & $\begin{array}{l}\text { Revised/Rotterdam } \\
\mathbf{2 0 0 3} \text { criteria }\end{array}$ & $\begin{array}{l}\text { Androgen Excess- } \\
\text { PCOS criteria }\end{array}$ \\
\hline $\begin{array}{l}\text { Chronic } \\
\text { anovulation }\end{array}$ & Oligo/anovulation & $\begin{array}{l}\text { Clinical and/or } \\
\text { biochemical signs of } \\
\text { hyperandrogenism }\end{array}$ \\
$\begin{array}{l}\text { Clinical and/or } \\
\text { biochemical signs of } \\
\text { hyperandrogenism }\end{array}$ & $\begin{array}{l}\text { Clinical and/or } \\
\text { biochemical signs of } \\
\text { hyperandrogenism }\end{array}$ & $\begin{array}{l}\text { Ovarian dysfunction } \\
\text { (defined by oligo/ } \\
\text { anovulation or } \\
\text { polycystic morphology } \\
\text { or both) }\end{array}$ \\
& $\begin{array}{l}\text { Polycystic ovarian } \\
\text { morphology in the } \\
\text { absence of a dominant } \\
\text { follicle }>20 \text { mm } \\
2 \text { of } 3 \text { criteria needed }\end{array}$ & \\
\hline $\begin{array}{l}\text { Both criteria } \\
\text { needed }\end{array}$ & \begin{tabular}{l} 
Both criteria needed \\
\hline
\end{tabular}
\end{tabular}

Note: All three require the exclusion of other endocrinopathies.

Abbreviations: PCOS, polycystic ovarian syndrome; NIH, National Institutes of Health. leads to infertility. As such, a typical evaluation for a patient presenting with infertility and irregular periods or ovulation includes a targeted history and physical examination with laboratory analysis for features of PCOS and other etiologies for anovulation (Table 2).

Ovulatory dysfunction affects approximately $25 \%$ of infertile couples, ${ }^{17}$ and the World Health Organization has classified anovulatory dysfunction into three broad categories based on the underlying pathophysiology, which is defined by levels of serum gonadotropins, ie, follicle-stimulating hormone (FSH), luteinizing hormone (LH), and estradiol. Category 1 anovulatory disorder is comprised of patients with low gonadotropin levels, often referred to as hypogonadotrophic hypogonadism. Category 1 essentially refers to hypothalamic or pituitary dysfunction resulting in abnormal or absent stimulation of ovarian function, including follicular development and steroidogenesis. Category 2 is comprised of patients with normal FSH, LH, and estrogen levels and is referred to as eugonadotropic eugonadism. Although an elevated $\mathrm{LH}$ to $\mathrm{FSH}$ ratio $(>2)$ is a common finding in PCOS, it is not universally seen and is not diagnostic of PCOS. PCOS sufferers constitute upwards of $80 \%$ of category 2 anovulation, and the majority of all-cause anovulation. ${ }^{18,19}$ Finally, category 3 anovulation refers to patients with elevated FSH and LH levels but low estradiol, which is associated with diminished ovarian reserve or premature ovarian insufficiency. Distinguishing the specific category of anovulation is crucial to developing a treatment strategy. However, these types of anovulation are not mutually exclusive, and in some cases, PCOS patients may also have altered or diminished release of gonadotropins (category 1) or ovarian senescence (category 3). Finally, other endocrinopathies,

Table 2 Assessment of endocrine function in patients with PCOS

\begin{tabular}{ll}
\hline Endocrine screening & Laboratory test \\
\hline Thyroid & TSH \\
Pituitary & Prolactin \\
Androgen excess & Total and free testosterone, \\
& DHEA-S, SHBG \\
Congenital adrenal hyperplasia & I7-OH progesterone \\
Cushing syndrome & Evening salivary cortisol \\
& 24-hour urine cortisol \\
& Overnight dexamethasone \\
& suppression test \\
Insulin resistance/glucose & HbA \\
intolerance & Oral glucose tolerance test \\
Ovarian reserve testing & FSH, LH, AMH, E2 \\
\hline
\end{tabular}

Abbreviations: TSH, thyroid-stimulating hormone; DHEA-S, dehydroepiandrostenedione sulfate; 17-OH, 17-hydroxyprogesterone; SHBG, sex hormone binding globulin; $\mathrm{HbA}_{1 \mathrm{c}}$, glycosylated hemoglobin; $\mathrm{FSH}$, follicle-stimulating hormone; LH, leutinizing hormone; AMH, anti-Mullerian hormone; E2, estradiol; PCOS, polycystic ovarian syndrome. 
including thyroid, pituitary, and adrenal disease, must be excluded and metabolic comorbidities addressed prior to initiating infertility treatment.

This paper provides a stepwise approach to the treatment of subfertility found in women with PCOS. Lifestyle interventions are described first, followed by oral treatments, and ending with more intensive strategies such as surgical interventions or assisted reproductive techniques.

\section{Lifestyle modification}

The prevalence of overweight and obesity in patients with PCOS ranges between $10 \%$ and $80 \%{ }^{4,20,21}$ in all populations studied. In the USA, the prevalence of obesity in women with PCOS is up to $80 \%,{ }^{5}$ while in European countries the rate varies from a low of $12 \%$ in Italian women to a high of $26.3 \%$ in German women. ${ }^{22}$

In light of the potential metabolic dysfunction associated with obesity and PCOS, the first line of treatment should be lifestyle modification in the form of diet and exercise. ${ }^{23,24}$ Weight loss has been shown to decrease the effects of androgens, increase ovulation, and improve insulin sensitivity. ${ }^{25-27}$ The randomized controlled trials that have studied lifestyle interventions point towards significant reproductive and metabolic benefits of weight loss, and have demonstrated that these benefits can be achieved with little absolute weight change. ${ }^{24,28}$ Adopting a diet with as little as a $500 \mathrm{kcal} /$ day reduced energy content can lead to a decrease in up to $10 \%$ of body weight by one year. Some experts recommend a balanced diet with less than $30 \%$ from fat and less than $10 \%$ from saturated fat, with increased fiber, whole grains, and vegetables. ${ }^{29}$ Exercise added to weight loss regimens showed benefits that were independent of weight loss. ${ }^{30-32}$ In spite of copious data in regards to the benefits of weight loss, there is inconclusive evidence that dietary changes can be sustained with weight loss over the long term. ${ }^{33,34}$ It is clear from the literature, though, that obese women with PCOS exhibit an attenuated response and lower pregnancy rates with medications for induction of ovulation. ${ }^{35,36}$

The current options for pharmacologically induced weight loss are limited. The results obtained using these drugs are very modest, and the side effects and risk profile have limited their use in the populations they are intended for. In the USA, there are only three weight loss drugs approved by the US Food and Drug Administration, and all have been shown to be minimally effective in producing clinically significant weight loss at one year (a decrease of 5\%), but none have been shown to decrease cardiovascular morbidity or mortality when compared with placebo by the end of one year. ${ }^{37}$ Orlistat, the only drug of the three to be approved in both Europe and the USA, ${ }^{38}$ works by inhibiting pancreatic lipase, thereby partially blocking the hydrolysis and absorption of dietary triglycerides. It is limited by its side effect profile, which includes oily spotting and flatus with discharge. ${ }^{39}$ Lorcaserin, a serotonin receptor agonist, and phentermine/topiramate, a stimulant, act centrally via slightly different mechanisms to depress appetite. Both have drug labels that include warnings about memory, attention, language problems, and depression. Unique to lorcaserin are warnings of valvular heart disease and euphoria, while the phentermine/topiramate combination has the added label warnings of metabolic acidosis, increased heart rate, anxiety, insomnia, and elevated creatinine levels. ${ }^{40}$ The weight loss demonstrated with lorcaserin and the phentermine/topiramate combination was significant, but only when used as adjuncts to low-calorie diets and exercise regimens. ${ }^{41}$ All three of the medications have been contraindicated during pregnancy and none have been studied specifically in the obese, infertile, PCOS patient.

If lifestyle modification, diet, and exercise are unsuccessful in achieving normal reproductive function, the final option for weight loss is bariatric surgery in some women. Bariatric surgery has been shown to restore regular menstrual cycles and ovulation in this population. ${ }^{42}$ Limited data have suggested a return of normal fertility in an unselected obese population following a bariatric procedure. ${ }^{43}$ Recently, data have supported a paradigm shift to offering these surgeries earlier in the treatment process. ${ }^{44}$ Early utilization of bariatric surgery ${ }^{45}$ in morbidly obese patients has the potential to lead rapidly to sustained weight loss and normalization of many comorbidities, including infertility. However, the standard practice in the USA is still that bariatric surgery should be reserved for patients who are unable to lose weight conventionally and for those whose body mass index would justify such an intervention. UK and German attitudes appear to be coincident with the US view of bariatric surgery as a last resort after lifestyle interventions have failed. ${ }^{46,47}$ Women should wait 12-24 months after bariatric surgery before pursuing pregnancy. ${ }^{48}$ It is incumbent on each provider to weigh the benefit of surgery versus this delay, especially in older women and/or those with decreased ovarian function.

\section{Oral agents}

\section{Insulin sensitizers}

Metformin is an insulin-sensitizing agent commonly used to treat non-insulin dependent diabetes mellitus and has been demonstrated to be safe during pregnancy 
(Pregnancy Class B). This biguanide medication has been utilized to treat the glucose intolerance associated with PCOS and has been shown to result in greater weight loss than placebo in a number of studies in PCOS patients. ${ }^{49-51}$ Higher doses (1,500-2,000 mg daily) of this medication may be more effective for weight loss. Gastrointestinal side effects, including bloating, flatulence, and diarrhea, are common at higher doses, and up to $5 \%$ of patients discontinue use secondary to these symptoms. ${ }^{52}$ Fewer side effects are seen with extended-release formulations, and some patients prefer the liquid form.

In anovulatory women with PCOS, the net effect of metformin is to decrease insulin, $\mathrm{LH}$, and androgen levels. A recent meta-analysis including nine studies and over 500 subjects showed that metformin had similar effects in terms of improving blood glucose and insulin levels when compared with lifestyle modification. ${ }^{53}$ Numerous early studies suggested a profound beneficial effect on fertility, leading to the suggestion that metformin should be a single-agent, first-line therapy for all women with PCOS. ${ }^{52,54}$ However, sentinel work by the NIH-sponsored Reproductive Medicine Network indicated that metformin should not be used as a single agent for infertility associated with PCOS. ${ }^{51}$ A very recent meta-analysis including 44 trials and almost 4,000 women also showed no improvement in live birth rate when compared with placebo, but the clinical pregnancy rate was higher with the use of metformin. ${ }^{55}$ Other insulinsensitizing agents have not been extensively studied because they have unfavorable pregnancy risk profiles.

\section{Selective estrogen receptor modulators}

The most extensively studied and only agent approved for use in the USA for induction of ovulation, clomiphene citrate, is an oral selective estrogen receptor modulator. ${ }^{56}$ It is the most common initial ovulation induction medication in use today. ${ }^{51}$ The drug's action is to centrally block the negative feedback that estrogen typically causes. The hypothalamus is released from normal feedback inhibition, leading to higher circulating levels of ovulatory hormones and hence follicular development and growth. ${ }^{57}$ The typical regimen for clomiphene citrate is to start at $50 \mathrm{mg}$ daily 2-5 days following the onset of a natural or progestin-induced menses. ${ }^{58}$ It has been shown that anovulatory women with PCOS would benefit from an immediate start rather than a progestin-induced withdrawal bleed prior to starting clomiphene citrate, with higher conception and live birth rates demonstrated in this study group ${ }^{59}$ however, this is not universally accepted practice at this time. The typical dosing schedule allows for increasing the daily dose by $50 \mathrm{mg}$ each cycle until a peak dosage of $250 \mathrm{mg}$ per day is achieved, although the higher doses are off-label because the US Food and Drug Administration has only approved dosing up to $150 \mathrm{mg}$ daily. In general, this conventional step-up regimen for clomiphene citrate results in an overall cumulative pregnancy rate of 55\%-73\% and should only be continued for six ovulatory cycles and at the lowest dose necessary to produce ovulation. ${ }^{23,60}$

According to the results of the Treatment of Infertility in Women with Polycystic Ovary Syndrome (PPCOS I) trial, the only large-scale randomized controlled study adequately powered to study live birth rate, the live birth rate approached normal fecundity levels at $23 \%$ after 6 months. Ovulation rates reached $49 \%$ and the pregnancy rate reached $30 \%{ }^{51}$ Another finding of the PPCOS I study was data supporting avoidance of a progestin withdrawal bleed, because pregnancy and live birth rates were higher when induction of ovulation was started without progestin withdrawal bleed, even though the ovulation rate was higher in those who had progestin withdrawal bleeding. ${ }^{61}$ Patients should be aware of the most common side effects, which include hot flashes, headaches, and moodiness, and be informed of the most serious side effects, such as visual changes, chest pain, seizures, and stroke. The most important adverse effect is the increased rate of multiple gestation, which is approximately $8 \% .{ }^{51,62}$ If pregnancy is not achieved after six cycles, more aggressive approaches are indicated. ${ }^{63}$

\section{Aromatase inhibitors}

This class of drugs, as the name implies, inhibits the actions of the enzyme aromatase, which is responsible for the peripheral conversion of androgens to estrogens. As such, there is an antiestrogenic effect, and less negative feedback to the hypothalamus results in higher circulating FSH, which in turn stimulates follicular development and ovulation. ${ }^{64}$ The most common of these drugs are letrozole and anastrozole, but since anastrozole was shown to be less effective than clomiphene citrate in Phase II studies, its use has declined. ${ }^{65,66}$ Unlike clomiphene citrate, the use of letrozole as an ovulation induction agent is off-label. The typical starting dose is $2.5 \mathrm{mg}$ daily, starting on day 3 post an induced bleed or natural bleeding episode, in the same manner as clomiphene citrate is taken. Usually, the dose is increased by $2.5 \mathrm{mg}$ until a response is achieved; however, there are some who advocate for using a single high dose of $20 \mathrm{mg} .{ }^{67}$ Unfortunately, there have been no randomized controlled trials regarding optimal dosing. ${ }^{64,68}$

A recent meta-analysis demonstrated a significantly higher ovulation rate per patient with letrozole versus clomiphene 
citrate, but no other parameter demonstrated superiority of either drug. Based on their findings, the authors could not recommend letrozole as a first-line therapy to replace clomiphene citrate. ${ }^{69}$ Recently, the NIH-funded Reproductive Medicine Network performed PPCOSII (Pregnancy in Polycystic Ovary Syndrome II), a double-blind, multicenter, randomized, controlled study that directly compared clomiphene citrate versus letrozole for anovulatory infertility in women with PCOS. This landmark trial showed a significant difference in ovulation (61.7\% for letrozole versus $48.3 \%$ for clomiphene citrate, $P<0.0001)$ and live birth rates $(27.5 \%$ for letrozole versus $19.2 \%$ for clomiphene citrate, $P=0.007$ ). It should be noted that the $44 \%$ higher live birth rate seen with letrozole was achieved in a population with a high body mass index and longstanding infertility. The authors postulate that their findings will lead to a change in first line therapy for ovulatory dysfunction associated with PCOS (paper in press, NEJM, 2014).

\section{Combination or sequential oral treatments}

Metformin and clomiphene citrate have been compared extensively with each other and in combination. ${ }^{51,52,70}$ There appears to be an increase in ovulation rate and pregnancy rate when the two are used in combination, but not in the live birth rate in comparison with clomiphene citrate alone. ${ }^{71}$ Patients with insulin resistance may benefit from the combination of metformin and clomiphene citrate compared with either agent used alone. ${ }^{51,71}$ A large multicenter trial also suggested that obese women, with a body mass index $>27$, had improved outcomes following pretreatment with 2,000 mg of metformin daily. Addition of metformin to standard infertility treatment increased the pregnancy rate by 1.6 -fold. ${ }^{72}$

The oral contraceptive pill is commonly used to treat menstrual dysfunction and decrease symptoms of androgen excess (hirsutism and acne) in patients with PCOS. Although many patients are not interested in delaying the start of fertility treatment, 2 months of treatment with the oral contraceptive pill prior to induction of ovulation with clomiphene citrate may improve the observed rate of ovulation and pregnancy by suppressing androgen levels. ${ }^{73}$

Another approach to nonresponders could be sequential use of oral ovulation induction agents without a progesterone withdrawal bleed. One such protocol involves starting clomiphene citrate at the typical $50 \mathrm{mg}$ dose. If inadequate follicular growth is noted, the dose can be increased by $50 \mathrm{mg}$ for another round of treatment, without an intervening menses, until ovulation is achieved or the maximal dose of
$150 \mathrm{mg}$ daily is used. ${ }^{74,75}$ A study that included this protocol demonstrated a significantly higher ovulation rate with the stair-step protocol (64\% versus $22 \%$ ) and a shortened time to ovulation (23-35 days versus 55-88 days) when compared with the traditional regimen. Similar clinical pregnancy and live birth rates were demonstrated with the traditional approach as compared with sequential therapy. ${ }^{75}$

\section{Advanced therapy Gonadotropins}

A subset of PCOS patients will require injectable gonadotropins for induction of ovulation. These treatment regimens require close monitoring by serum sampling and transvaginal ultrasound to reduce the risk of multiple pregnancies and ovarian hyperstimulation syndrome. In the commonly used low-dose step-up protocol, exogenous FSH is initiated at a low dose and gradually increased until follicular development is noted, thus limiting the likelihood of high-order multiple pregnancies resulting from multiple follicular growth. ${ }^{23,76}$ The starting dose is 37.5-75 IU/day, maintained for 1 week and then increased every 7 days until follicular growth is demonstrated. ${ }^{77,78}$ Successful stimulation is defined as a maximum of two dominant follicles measuring at least $\geq 16 \mathrm{~mm}$, or one follicle $\geq 16 \mathrm{~mm}$ and two smaller follicles no more than $14 \mathrm{~mm}$ in diameter. Cycle cancellation is recommended if follicular development exceeds these parameters. ${ }^{79}$ This regimen can be repeated for a maximum of six cycles, with subsequent cycles starting closer to the dosage that led to a response the first time around. When used following failure of clomiphene, the cumulative 2-year singleton live birth rate exceeded $70 \%{ }^{80}$

\section{Surgery}

Laparoscopic ovarian surgery is considered a second-line or third-line therapy for ovulatory dysfunction associated with PCOS. ${ }^{23}$ Traditionally, a wedge of the ovaries was removed to suppress androgen production and allow the ovary to resume normal steroid production and follicular development. Minimally invasive approaches with ovarian drilling have replaced this traditional method. One approach is to drill multiple small holes through the surface and stroma of the ovary using either laser or diathermy in as few as four but no more than ten separate locations. Ovarian drilling has results that are comparable with the more invasive wedge resection. Potential adverse outcomes include surgical complications, post-surgical adhesion formation, and possible premature ovarian failure. ${ }^{81,82}$ Proponents of ovarian drilling argue that it has lower multiple order pregnancy rates and no 
risk of ovarian hyperstimulation syndrome compared with gonadotropins. It has the added advantage of being a single treatment as opposed to multiple rounds for induction of ovulation. Thus, it may have lower direct and indirect costs. ${ }^{23}$ However, controversy exists regarding pregnancy outcomes following ovarian drilling. A 2007 Cochrane review, which included nine studies, showed pregnancy and live birth rates comparable with those of induction of ovulation with gonadotropins. ${ }^{83}$ Conversely, a 2012 Cochrane review by the same lead author demonstrated a lower live birth rate with ovarian drilling when compared with clomiphene citrate and metformin, and comparable rates of success when compared with clomiphene citrate or letrozole alone. ${ }^{84}$

\section{Assisted reproductive techniques}

Intrauterine insemination has been shown to improve the success rates compared with timed intercourse for couples with unexplained infertility following clomiphene citrate and gonadotropins. ${ }^{85}$ However, there are no randomized controlled trials comparing the pregnancy rates of intrauterine insemination versus timed intercourse for women with PCOS. In the absence of male factor infertility or abnormal semen parameters, timed intercourse is recommended by most authors. Intrauterine insemination would be required for women who need to use donor semen, given that intrauterine insemination has been demonstrated to be superior to intracervical insemination. ${ }^{86}$

Although traditionally, the last line of fertility treatment for women with PCOS would be assisted reproduction or in vitro fertilization, some clinicians have advocated for early utilization of this treatment option. In vitro fertilization involves controlled ovarian hyperstimulation or superovulation with injectable gonadotropins. Follicular development and oocyte maturation is determined by monitoring with transvaginal ultrasound and measurement of serum estradiol levels. The optimal stimulation protocol for PCOS patients has not been established, but overall, oocyte retrieval is typically done transvaginally following superovulation with gonadotropins. The gametes are then fertilized in vitro and undergo culture for 3-5 days. Cleavage or blastocyst stage embryos can be transferred back to the patient in a fresh cycle or frozen for future use. Although PCOS patients have cycle cancellation and ovarian hyperstimulation syndrome more often than non-PCOS patients when undergoing assisted reproduction, the fertilization and clinical pregnancy rates appear to be similar. ${ }^{86}$ The true benefit of in vitro fertilization may lie in its ability to reduce the risk of multiple pregnancies by limiting the number of embryos transferred with increasing emphasis on single embryo transfers.

\section{Conclusion}

A stepwise approach to the treatment of infertility in PCOS will allow most patients to achieve pregnancy and a live birth. The treatment approach should begin with lifestyle modifications such as diet and exercise in order to effect weight loss. The first-line oral agents include clomiphene citrate and letrozole, with recent evidence favoring the use of letrozole. Metformin plays a key role in patients with glucose intolerance and obesity as an adjunct to induction of ovulation. Consideration must be given to avoidance of in vitro fertilization and multiple pregnancies with careful monitoring when utilizing superovulation with gonadotropins. Laparoscopic ovarian drilling may be considered as a second-line treatment in select populations. In vitro fertilization also plays a role in the treatment of PCOS-associated infertility when one considers the high success rates and potentially lower rate of multiple gestations. Although the optimum management of subfertility in PCOS has not been determined and may vary considerable amongst the different phenotypes, this review provides a framework for practitioners to formulate an individualized treatment plan for their patients.

\section{Disclosure}

The authors report no conflicts of interest in this work.

\section{References}

1. March WA, Moore VM, Willson KJ, Phillips DI, Norman RJ, Davies MJ. The prevalence of polycystic ovary syndrome in a community sample assessed under contrasting diagnostic criteria. Hum Reprod. 2010;25(2):544-551.

2. Azziz R, Woods KS, Reyna R, Key TJ, Knochenhauer ES, Yildiz BO. The prevalence and features of the polycystic ovary syndrome in an unselected population. J Clin Endocrinol Metab. 2004;89(6): 2745-2749.

3. Knochenhauer ES, Key TJ, Kahsar-Miller M, Waggoner W, Boots LR, Azziz R. Prevalence of the polycystic ovary syndrome in unselected black and white women of the southeastern United States: a prospective study. J Clin Endocrinol Metab. 1998;83(9):3078-3082.

4. Asunción M, Calvo RM, Millán JLS, Sancho J, Avila S, EscobarMorreale HF. A prospective study of the prevalence of the polycystic ovary syndrome in unselected Caucasian women from Spain. J Clin Endocrinol Metab. 2000;85(7):2434-2438.

5. Diamanti-Kandarakis E, Dunaif A. Insulin resistance and the polycystic ovary syndrome revisited: an update on mechanisms and implications. Endocr Rev. 2012;33(6):981-1030.

6. Azziz R, Marin C, Hoq L, Badamgarav E, Song P. Health care-related economic burden of the polycystic ovary syndrome during the reproductive life span. J Clin Endocrinol Metab. 2005;90(8):4650-4658.

7. Goverde AJ, van Koert AJ, Eijkemans MJ, et al. Indicators for metabolic disturbances in anovulatory women with polycystic ovary syndrome diagnosed according to the Rotterdam consensus criteria. Hum Reprod. 2009;24(3):710-717. 
8. Kumarapeli V, Seneviratne Rde A, Wijeyaratne CN, Yapa RM, Dodampahala SH. A simple screening approach for assessing community prevalence and phenotype of polycystic ovary syndrome in a semi-urban population in Sri Lanka. Am J Epidemiol. 2008;168(3):321-328.

9. Stein IF, Leventhal ML. Amenorrhea associated with bilateral polycystic ovaries. Am J Obstet Gynecol. 1935;29:181-191.

10. Fauser BC, Tarlatzis BC, Rebar RW, et al. Consensus on women's health aspects of polycystic ovary syndrome (PCOS): the Amsterdam ESHRE/ASRM-Sponsored 3rd PCOS Consensus Workshop Group. Fertil Steril. 2012;97(1):28-38. e25.

11. Dunaif A, Fauser BC. Renaming PCOS - a two-state solution. J Clin Endocrinol Metab. 2013;98(11):4325-4328.

12. Rotterdam ESHRE/ASRM-Sponsored PCOS Consensus Workshop Group. Revised 2003 consensus on diagnostic criteria and longterm health risks related to polycystic ovary syndrome. Fertil Steril. 2004;81(1):19-25.

13. Azziz R, Carmina E, Dewailly D, et al. The Androgen Excess and PCOS Society criteria for the polycystic ovary syndrome: the complete task force report. Fertil Steril. 2009;91(2):456-488.

14. Zawadzki J, Dunaif A. Diagnostic criteria for polycystic ovary syndrome: towards a rational approach. In: Dunaif A, editor. Polycystic Ovary Syndrome. Volume 377. Boston, MA, USA: Blackwell Scientific; 1992.

15. Azziz R, Carmina E, Dewailly D, et al. Position statement: criteria for defining polycystic ovary syndrome as a predominantly hyperandrogenic syndrome: an Androgen Excess Society guideline. J Clin Endocrinol Metab. 2006;91(11):4237-4245.

16. Geisthovel F, Rabe T. The ESHRE/ASRM consensus on polycystic ovary syndrome (PCOS) - an extended critical analysis. Reprod Biomed Online. 2007;14(4):522-535.

17. ACOG Committee on Practice Bulletins-Gynecology. ACOG Practice Bulletin. Clinical management guidelines for obstetriciangynecologists number 34, February 2002. Management of infertility caused by ovulatory dysfunction. American College of Obstetricians and Gynecologists. Obstet Gynecol. 2002;99(2):347-358.

18. [No authors listed]. Agents stimulating gonadal function in the human. Report of a WHO scientific group. World Health Organ Tech Rep Ser. 1973;514:1-30.

19. Thessaloniki ESHRE/ASRM-Sponsored PCOS Consensus Workshop Group. Consensus on infertility treatment related to polycystic ovary syndrome. Fertil Steril. 2008;89(3):505-522.

20. Zhang HY, Guo CX, Zhu FF, Qu PP, Lin WJ, Xiong J. Clinical characteristics, metabolic features, and phenotype of Chinese women with polycystic ovary syndrome: a large-scale case-control study. Arch Gynecol Obstet. 2013;287(3):525-531.

21. Enrico C, Richard SL, Kelly S, Jennifer L, Rogerio AL. Difference in body weight between American and Italian women with polycystic ovary syndrome: influence of the diet. Hum Reprod. 2003;18(11) 2289-2293.

22. van Vliet-Ostaptchouk JV, Nuotio ML, Slagter SN, et al. The prevalence of metabolic syndrome and metabolically healthy obesity in Europe: a collaborative analysis of ten large cohort studies. BMC Endocr Disord. 2014;14(1):9.

23. Thessaloniki ESHRE/ASRM-Sponsored PCOS Consensus Workshop Group. Consensus on infertility treatment related to polycystic ovary syndrome. Hum Reprod. 2008;23(3):462-477.

24. Moran LJ, Pasquali R, Teede HJ, Hoeger KM, Norman RJ. Treatment of obesity in polycystic ovary syndrome: a position statement of the Androgen Excess and Polycystic Ovary Syndrome Society. Fertil Steril. 2009;92(6):1966-1982.

25. Kiddy DS, Hamilton-Fairley D, Bush A, et al. Improvement in endocrine and ovarian function during dietary treatment of obese women with polycystic ovary syndrome. Clin Endocrinol. 1992;36(1):105-111.

26. Kiddy DS, Sharp PS, White DM, et al. Differences in clinical and endocrine features between obese and non-obese subjects with polycystic ovary syndrome: an analysis of 263 consecutive cases. Clin Endocrinol. 1990;32(2):213-220.
27. Guzick DS, Wing R, Smith D, Berga SL, Winters SJ. Endocrine consequences of weight loss in obese, hyperandrogenic, anovulatory women. Fertil Steril. 1994;61(4):598-604.

28. Moran LJ, Hutchison SK, Norman RJ, Teede HJ. Lifestyle changes in women with polycystic ovary syndrome. Cochrane Database Syst Rev. 2011;7:CD007506.

29. Gower BA, Chandler-Laney PC, Ovalle F, et al. Favourable metabolic effects of a eucaloric lower-carbohydrate diet in women with PCOS. Clin Endocrinol. 2013;79(4):550-557.

30. Brenda B, Karen C, Donna C. Effects of exercise and nutritional counseling in women with polycystic ovary syndrome. Appl Physiol Nutr Metab. 2006;31(4):384-391.

31. Bruce CR, Kriketos AD, Cooney GJ, Hawley JA. Disassociation of muscle triglyceride content and insulin sensitivity after exercise training in patients with type 2 diabetes. Diabetologia. 2004;47(1): 23-30.

32. O'Gorman DJ, Karlsson HKR, McQuaid S, et al. Exercise training increases insulin-stimulated glucose disposal and GLUT4 (SLC2A4) protein content in patients with type 2 diabetes. Diabetologia. 2006;49(12):2983-2992.

33. Mastellos N, Gunn LH, Felix LM, Car J, Majeed A. Transtheoretical model stages of change for dietary and physical exercise modification in weight loss management for overweight and obese adults. Cochrane Database Syst Rev. 2014;2:CD008066.

34. Anderson JW, Konz EC, Frederich RC, Wood CL. Long-term weight-loss maintenance: a meta-analysis of US studies. Am J Clin Nutr. 2001;74(5):579-584.

35. Rausch ME, Legro RS, Barnhart HX, et al. Predictors of pregnancy in women with polycystic ovary syndrome. J Clin Endocrinol Metab. 2009;94(9):3458-3466.

36. Imani B, Eijkemans MJ, te Velde ER, Habbema JD, Fauser BC Predictors of patients remaining anovulatory during clomiphene citrate induction of ovulation in normogonadotropic oligoamenorrheic infertility. J Clin Endocrinol Metab. 1998;83(7):2361-2365.

37. Yanovski SZ, Yanovski JA. Long-term drug treatment for obesity: a systematic and clinical review. JAMA. 2014;311(1):74-86.

38. Baretic M. Obesity drug therapy. Minerva Endocrinol. 2013;38(3): 245-254.

39. Leblanc ES, O'Connor E, Whitlock EP, Patnode CD, Kapka T. Effectiveness of primary care-relevant treatments for obesity in adults: a systematic evidence review for the US Preventive Services Task Force. Ann Intern Med. 2011;155(7):434-447.

40. Woloshin S, Schwartz LM. The new weight-loss drugs, lorcaserin and phentermine-topiramate: slim pickings? JAMA Intern Med. 2014;174(4):615-619.

41. Fleming JW, McClendon KS, Riche DM. New obesity agents: lorcaserin and phentermine/topiramate. Ann Pharmacother. 2013; 47(7-8):1007-1016.

42. Escobar-Morreale HF, Botella-Carretero JI, Alvarez-Blasco F, Sancho J, San Millan JL. The polycystic ovary syndrome associated with morbid obesity may resolve after weight loss induced by bariatric surgery. J Clin Endocrinol Metab. 2005;90(12):6364-6369.

43. Musella M, Milone M, Bellini M, Sosa Fernandez LM, Leongito M, Milone F. Effect of bariatric surgery on obesity-related infertility Surg Obes Relat Dis. 2012;8(4):445-449.

44. Malik SM, Traub ML. Defining the role of bariatric surgery in polycystic ovarian syndrome patients. World J Diabetes. 2012;3(4): 71-79.

45. Costello MF, Ledger WL. Evidence-based management of infertility in women with polycystic ovary syndrome using surgery or assisted reproductive technology. Women's Health. 2012;8(3):291-300.

46. Guelinckx I, Devlieger R, Vansant G. Reproductive outcome after bariatric surgery: a critical review. Hum Reprod Update. 2009;15(2): 189-201.

47. Stroh C, Hohmann U, Lehnert H, Manger T. [PCO syndrome - is it an indication for bariatric surgery?]. Zentralblatt fur Chirurgie. 2008;133(6):608-610. German. 
48. American College of Obstetricians and Gynecologists. ACOG practice bulletin no 105: bariatric surgery and pregnancy. Obstet Gynecol. 2009;113(6):1405-1413.

49. Tang T, Glanville J, Hayden CJ, White D, Barth JH, Balen AH. Combined lifestyle modification and metformin in obese patients with polycystic ovary syndrome. A randomized, placebo-controlled, doubleblind multicentre study. Hum Reprod. 2006;21(1):80-89.

50. Tang T, Glanville J, Orsi N, Barth JH, Balen AH. The use of metformin for women with PCOS undergoing IVF treatment. Hum Reprod. 2006;21(6):1416-1425.

51. Legro RS, Barnhart HX, Schlaff WD, et al. Clomiphene, metformin, or both for infertility in the polycystic ovary syndrome. $N$ Engl J Med. 2007;356(6):551-566.

52. Barbieri RL. Clomiphene versus metformin for ovulation induction in polycystic ovary syndrome: the winner is. J Clin Endocrinol Metab. 2007;92(9):3399-3401.

53. Domecq JP, Prutsky G, Mullan RJ, et al. Lifestyle modification programs in polycystic ovary syndrome: systematic review and metaanalysis. J Clin Endocrinol Metab. 2013;98(12):4655-4663.

54. Nestler JE, Jakubowicz DJ, Evans WS, Pasquali R. Effects of metformin on spontaneous and clomiphene-induced ovulation in the polycystic ovary syndrome. N Engl J Med. 1998;338(26):1876-1880.

55. Tang T, Lord JM, Norman RJ, Yasmin E, Balen AH. Insulin-sensitising drugs (metformin, rosiglitazone, pioglitazone, D-chiro-inositol) for women with polycystic ovary syndrome, oligo amenorrhoea and subfertility. Cochrane Database Syst Rev. 2012;5:CD003053.

56. Practice Committee of the American Society for Reproductive Medicine. Use of clomiphene citrate in women. Fertil Steril. 2006; 86(5 Suppl 1):S187-S193.

57. Adashi EY. Clomiphene citrate: mechanism(s) and site(s) of action a hypothesis revisited. Fertil Steril. 1984;42(3):331-344.

58. Practice Committee of the American Society for Reproductive Medicine. Use of clomiphene citrate in infertile women: a committee opinion. Fertil Steril. 2013;100(2):341-348.

59. Lewis V, Queenan J Jr, Hoeger K, Stevens J, Guzick DS. Clomiphene citrate monitoring for intrauterine insemination timing: a randomized trial. Fertil Steril. 2006;85(2):401-406.

60. Imani B, Eijkemans MJ, te Velde ER, Habbema JD, Fauser BC. A nomogram to predict the probability of live birth after clomiphene citrate induction of ovulation in normogonadotropic oligoamenorrheic infertility. Fertil Steril. 2002;77(1):91-97.

61. Diamond MP, Kruger M, Santoro N, et al. Endometrial shedding effect on conception and live birth in women with polycystic ovary syndrome. Obstet Gynecol. 2012;119(5):902-908.

62. Schenker JG, Yarkoni S, Granat M. Multiple pregnancies following induction of ovulation. Fertil Steril. 1981;35(2):105-123.

63. Imani B, Eijkemans MJ, te Velde ER, Habbema JD, Fauser BC. Predictors of chances to conceive in ovulatory patients during clomiphene citrate induction of ovulation in normogonadotropic oligoamenorrheic infertility. J Clin Endocrinol Metab. 1999;84(5):1617-1622.

64. Casper RF, Mitwally MF. A historical perspective of aromatase inhibitors for ovulation induction. Fertil Steril. 2012;98(6):1352-1355.

65. Tredway D, Schertz JC, Bock D, Hemsey G, Diamond MP. Anastrozole single-dose protocol in women with oligo- or anovulatory infertility: results of a randomized phase II dose-response study. Fertil Steril. 2011;95(5):1725-1729.

66. Tredway D, Schertz JC, Bock D, Hemsey G, Diamond MP. Anastrozole vs clomiphene citrate in infertile women with ovulatory dysfunction: a phase II, randomized, dose-finding study. Fertil Steril. 2011;95(5): $1720-1724$.

67. Mitwally MF, Casper RF. Single-dose administration of an aromatase inhibitor for ovarian stimulation. Fertil Steril. 2005;83(1): 229-231.

68. Pritts EA. Letrozole for ovulation induction and controlled ovarian hyperstimulation. Curr Opin Obstet Gynecol. 2010;22(4):289-294.
69. Misso ML, Wong JL, Teede HJ, et al. Aromatase inhibitors for PCOS: a systematic review and meta-analysis. Hum Reptod Update. 2012;18(3):301-312.

70. Palomba S, Pasquali R, Orio F Jr, Nestler JE. Clomiphene citrate, metformin or both as first-step approach in treating anovulatory infertility in patients with polycystic ovary syndrome (PCOS): a systematic review of head-to-head randomized controlled studies and meta-analysis. Clin Endocrinol. 2009;70(2):311-321.

71. Siebert TI, Viola MI, Steyn DW, Kruger TF. Is metformin indicated as primary ovulation induction agent in women with PCOS? A systematic review and meta-analysis. Gynecol Obstet Invest. 2012;73(4):304-313.

72. Morin-Papunen L, Rantala AS, Unkila-Kallio L, et al. Metformin improves pregnancy and live-birth rates in women with polycystic ovary syndrome (PCOS): a multicenter, double-blind, placebo-controlled randomized trial. J Clin Endocrinol Metab. 2012;97(5):1492-1500.

73. Branigan EF, Estes MA. A randomized clinical trial of treatment of clomiphene citrate-resistant anovulation with the use of oral contraceptive pill suppression and repeat clomiphene citrate treatment. $\mathrm{Am} J$ Obstet Gynecol. 2003;188(6):1424-1428.

74. Bates GW, Shomento S, McKnight K, McLean HM. Novel clomiphene protocol in polycystic ovarian syndrome: Hurst et al. Am J Obstet Gynecol. 2009;200(5):586-587.

75. Hurst BS, Hickman JM, Matthews ML, Usadi RS, Marshburn PB. Novel clomiphene "stair-step" protocol reduces time to ovulation in women with polycystic ovarian syndrome. Am J Obstet Gynecol. 2009;200(5): 510.e511-510.e514.

76. Christin-Maitre S, Hugues JN; Recombinant FSH Study Group. A comparative randomized multicentric study comparing the step-up versus step-down protocol in polycystic ovary syndrome. Hum Reprod. 2003;18(8):1626-1631.

77. Polson DW, Mason HD, Saldahna MB, Franks S. Ovulation of a single dominant follicle during treatment with low-dose pulsatile follicle stimulating hormone in women with polycystic ovary syndrome. Clin Endocrinol. 1987;26(2):205-212.

78. Seibel MM, Kamrava MM, McArdle C, Taymor ML. Treatment of polycystic ovary disease with chronic low-dose follicle stimulating hormone: biochemical changes and ultrasound correlation. Int $J$ Fertil. 1984;29(1):39-43.

79. Kaplan PF, Patel M, Austin DJ, Freund R. Assessing the risk of multiple gestation in gonadotropin intrauterine insemination cycles. Am JObstet Gynecol. 2002;186(6):1244-1247.

80. Eijkemans MJ, Imani B, Mulders AG, Habbema JD, Fauser BC. High singleton live birth rate following classical ovulation induction in normogonadotrophic anovulatory infertility (WHO 2). Hum Reprod. 2003;18(11):2357-2362.

81. Kandil M, Selim M. Hormonal and sonographic assessment of ovarian reserve before and after laparoscopic ovarian drilling in polycystic ovary syndrome. BJOG. 2005;112(10):1427-1430.

82. Mercorio F, Mercorio A, Di Spiezio Sardo A, Barba GV, Pellicano M, Nappi C. Evaluation of ovarian adhesion formation after laparoscopic ovarian drilling by second-look minilaparoscopy. Fertil Steril. 2008;89(5):1229-1233.

83. Farquhar C, Lilford RJ, Marjoribanks J, Vandekerckhove P. Laparoscopic 'drilling' by diathermy or laser for ovulation induction in anovulatory polycystic ovary syndrome. Cochrane Database Syst Rev. 2007;3:CD001122.

84. Farquhar C, Brown J, Marjoribanks J. Laparoscopic drilling by diathermy or laser for ovulation induction in anovulatory polycystic ovary syndrome. Cochrane Database Syst Rev. 2012;6:CD001122.

85. Guzick DS, Sullivan MW, Adamson GD, et al. Efficacy of treatment for unexplained infertility. Fertil Steril. 1998;70(2):207-213.

86. Heijnen EM, Eijkemans MJ, Hughes EG, Laven JS, Macklon NS, Fauser BC. A meta-analysis of outcomes of conventional IVF in women with polycystic ovary syndrome. Hum Reprod Update. 2006;12(1): $13-21$. 
International Journal of Women's Health

Dovepress

\section{Publish your work in this journal}

The International Journal of Women's Health is an international, peerreviewed open-access journal publishing original research, reports, editorials, reviews and commentaries on all aspects of women's healthcare including gynecology, obstetrics, and breast cancer. The manuscript management system is completely online and includes Visit http://www.dovepress.com/testimonials.php to read real quotes from published authors.

Submit your manuscript here: http://www.dovepress.com/international-journal-of-womens-health-journal 